\title{
SER PESSOA NA HOSPITALIZACCÃO: RELATOS DE GESTANTES SOBRE AS RELAÇÕES ESTABELECIDAS COM A EQUIPE MULTIPROFISSIONAL
}

\author{
Being a Person in Hospitalization: Report of Pregnant Women on Relations Established with a \\ Multiprofessional Team
}

\author{
Ser Persona en la Hospitalización: Informe de las Mujeres Embarazadas sobre las Relaciones \\ Establecidas con un Equipo Multiprofesional
}

LEIHGE ROSELLE RONDON PEREIRA ANA RAFAELA PECORA CALHAO

\begin{abstract}
Resumo: Nesse estudo procuramos conhecer e analisar, na perspectiva das pacientes gestantes internadas em um hospital de ensino na cidade de Cuiabá-MT, como essas significam as relações estabelecidas com a equipe multiprofissional. Foram realizadas 11 entrevistas focalizadas, com adoção de atitudes facilitadoras de consideração positiva incondicional, congruência e compreensão empática, com pacientes que estiveram hospitalizadas durante o segundo semestre de 2015. Esse procedimento forneceu o instrumental teórico-metodológico baseado na criação de um clima facilitador, a partir dos fundamentos da Abordagem Centrada na Pessoa, o que permitiu explorar as significações pessoais das experiências com um acento afetivo ou emocional. O processamento ocorreu pelo software ALCESTE, análise pelo estudo das Classes apresentadas pelo software e discussões teóricas sobre as relações interpessoais de ajuda. O estudo destacou a atenção para: a comunicação dos procedimentos; a disposição para cuidados afetivos em que consideram a pessoa como centro em detrimento às técnicas; a importância para as significações pessoais, e as implicações das significações pessoais no processo de hospitalização. Exercer essa atenção pode contribuir para o desenvolvimento de relacionamentos que facilitem o processo de hospitalização.
\end{abstract}

Palavras-chave: Psicologia Humanista; Abordagem Centrada na Pessoa; Clima Facilitador; Percepção; Equipe de Assistência ao Paciente.

\begin{abstract}
In this study we try to understand and analyze, from the perspective of pregnant patients admitted to a teaching hospital in the city of Cuiabá-MT, how these women realize the relations established with a multi professional health care team. Eleven focused interviews were conducted, with the adoption of facilitative conditions from unconditional positive regard, congruence, and empathic understanding, with patients who were hospitalized during the second half of 2015. This provided the theoretical and methodological tools based on creating a facilitative climate, with the fundamentals of the Person Centered Approach, which allowed us to explore the self understanding experiences with an affective or emotional importance. Data processing was performed by ALCESTE software, analysis used the classes presented by the software as well as theoretical discussions on interpersonal helping relations. The study highlighted the attention to: communication procedures; the willingness to emotional care where they consider the person as the center rather than the technics; the importance for personal insights and implications of these in the hospitalization process. Accomplish such care can contribute to the development of relationships that facilitate the process of hospitalization.
\end{abstract}

Keywords: Humanistic Psychology; Person Centered Approach; Facilitative Climate; Perception; Patient Care Team.

Resumen: En este estudio tratamos de entender y analizar, desde la perspectiva de los pacientes embarazadas ingresados en un hospital universitario en la ciudad de Cuiabá-MT, ya que éstas significan las relaciones establecidas con un equipo multiprofesional. Llevamos a cabo 11 entrevistas focalizadas con la adopción de actitudes facilitadoras de consideración positiva incondicional, congruencia y la comprensión empática, con los pacientes que fueron hospitalizados durante la segunda mitad del año 2015. Este procedimiento proporciona el instrumental teórico-metodológico basadas en la creación de un clima facilitador, a partir de los fundamentos del Enfoque Centrado en la Persona, que nos permitió explorar las significaciones de las experiencias personales con un esfuerzo afectivo o emocional. Procesamiento ocurrió por el software ALCESTE, análisis en el estudio de las Clases presentada por el software y discusiones teóricas sobre las relaciones interpersonales de ayuda. El estudio puso de relieve la atención: comunicación de los procedimientos; la disposición a el cuidado afectivo cuando consideren a la persona como el centro en detrimento a las técnicas; la importancia para los significados personales e la implicaciones del significados personales en el proceso de hospitalización. El ejercicio dicha atención puede contribuir al desarrollo de las relaciones que facilitan el proceso de la hospitalización.

Palabras-clave: Psicología Humanista; Enfoque Centrado en la Persona; Clima Facilitador; Percepción; Grupo de Atencíon al Paciente. 


\section{Introdução}

Hospitais de ensino são aqueles caracterizados por um tripé de ações, trata-se de locais em que são desenvolvidos a docência, a pesquisa e a prestação do serviço de alta complexidade. Essas ações potencializam novas formas de ser profissional da saúde, fomentando contribuições para que as pessoas envolvidas no cuidado da pessoa adoecida possam refletir sobre a sua prática e por meio de estudos possam contribuir com os avanços teóricos (Araújo, 2014). Em um hospital de ensino na cidade de Cuiabá, em Mato Grosso, onde a pesquisa foi realizada, existe o Programa de Residência Integrada Multiprofissional em Saúde do Adulto e do Idoso com Ênfase em Atenção Cardiovascular. Nesse Programa um dos espaços para aprendizagens sobre a atenção cardiovascular é a Enfermaria de Ginecologia e Obstetrícia (GO), considerada referência estadual para Gestações de Alto Risco e Neoplasia, sendo que suas principais demandas de agravos gestacionais estão associadas com o sistema cardiovascular.

Ao atuarmos nessa Enfermaria, enquanto psicóloga residente e tutora do Programa, e ao participarmos do seu contexto, observamos que as mulheres internadas não se encontravam em sofrimento apenas pelo fenômeno biológico vivenciado, mas de modo concomitante estavam sendo afetadas por questões multifatoriais, de ordem biopsicossocial, incluindo-se aí as relacionais, sobretudo as que se referem aos cuidados de saúde disponibilizados pela equipe multiprofissional ${ }^{1}$.

Durante a internação hospitalar as pacientes interagem com pessoas que não se encontravam presentes em seu ciclo vivencial, como os membros da equipe multiprofissional. Essas novas relações produzem afetações nas pacientes, que se manifestam como fator significativo na internação hospitalar. Por meio da pesquisa buscamos, então, explorar as percepções singulares das pacientes, a partir de seus relatos, que explicitam as suas significações sobre as relações estabelecidas com a equipe multiprofissional.

Carl Rogers, psicólogo norte-americano, propositor da Abordagem Centrada na Pessoa (ACP), apresenta como um dos aspectos fundamentais de suas teorias as significações pessoais (Rogers, 1977). Sendo próprias do campo perceptivo, as significações pessoais apresentam a característica de apreciar os acentos afetivos, emocionais e relacionais de um processo experiencial, no qual é evidenciado mais as situações do presente do que as do passado, pois elas se movem para um fluxo em que os sentimentos estão em permanente mudança e são, assim, experimentados no momento em que ocorre o relato (Rogers, 2009).

Carl Rogers, internacionalmente conhecido por desenvolver trabalhos divergentes às proposições mais diretivas em Psicologia, teve como principal interesse a formulação de uma Teoria de Psicoterapia centrada na pessoa, cujo processo é es-

1 Nessa pesquisa entendemos por equipe multiprofissional, um grupo composto pelos diferentes profissionais da saúde que interagem com os pacientes durante a internação, como exemplo: médicos, enfermeiras, nutricionistas e psicólogos. tabelecido a partir da ênfase na dimensão afetiva sobre a intelectual. Essa proposta inicialmente voltada aos aspectos psicoterápicos, que culminou na explicitação de uma Teoria da Personalidade, Teoria do Funcionamento Ótimo da Personalidade, e Teoria das Relações Humanas de forma mais ampla, propondo estudos que ganharam atuações em diferentes campos, como no da psicoterapia, educação, das relações familiares, dos conflitos internacionais e culturais, que convergiram na proposta de uma Abordagem Centrada na Pessoa.

Rogers (2009) postula que os recursos para as soluções dos conflitos humanos estão presentes nas pessoas que os vivenciam. O teórico aponta que a melhor forma de prestar ajuda às pessoas em dificuldade é criando um clima de confiança e apoio, em que as pessoas possam acessar os seus próprios recursos na solução de seus problemas. Essa atmosfera promotora de autonomia, segundo o autor (Rogers,2009;1977b), direciona as pessoas para um estado de acordo interno, mais congruente, e para um funcionamento mais realístico.

As condições necessárias e suficientes para a mudança terapêutica de personalidade (Rogers, 1994) são apontadas pelo teórico, a saber: 1) Que duas pessoas estejam em contato psicológico; 2) Que a primeira, a quem chamaremos cliente, esteja num estado de incongruência, estando vulnerável ou ansiosa; 3) Que a segunda pessoa, a quem chamaremos de terapeuta, esteja congruente ou integrada na relação; 4) Que o terapeuta experiencie consideração positiva incondicional pelo cliente; 5) Que o terapeuta experiencie uma compreensão empática do esquema de referência interno do cliente e se esforce por comunicar esta experiência ao cliente; 6) Que a comunicação ao cliente da compreensão empática do terapeuta e da consideração positiva incondicional seja efetivada, pelo menos num grau mínimo.

Dessas condições, nos interessa destacar três atitudes (itens $3,4,5$ ), promotoras de um clima facilitador nas relações de ajuda, são elas: Congruência, Consideração Positiva Incondicional, e Compreensão Empática (Rogers, 2009; 1983), tais atitudes foram utilizadas durantes as entrevistas. A Congruência se refere ao estado de acordo interno, de autenticidade de quem esteja facilitando um processo de ajuda. Essa atitude permite que o facilitador crie condições para que o outro também acesse seus sentimentos e experiências sem a necessidade de apresentar artifícios ou comportamentos defensivos. Por Consideração Positiva Incondicional se entende uma atenção, para com o outro, baseada no respeito e na percepção de suas potencialidades, uma relação de afeição e segurança para que a pessoa também se perceba e se aceite. A Compreensão Empática se refere a capacidade de compreender, por meio fisionômico e verbal, as experiências e os sentimentos do outro e a significação que apresentam para ele, como também, conseguir comunicar essa compreensão (Rogers, 2009; 1983).

Nos hospitais,espaços de interação humana, nem sempre encontramos profissionais implicados no estabelecimento de relações facilitadoras com 
o usuário do serviço, apesar de, no Brasil, existir uma Política Nacional de Humanização, Humaniza SUS, (Brasil, 2008), que propõe a superação do modelo técnico-científico de cuidado. Essa política através do princípio da transversalidade, se utiliza de ferramentas e dispositivos para consolidar redes e vínculos, tendo como norte o contato e a comunicação. A ação de se relacionar, por meio da Política, potencializa o ideal de cuidados holísticos, no qual é apreciado a pessoa como um todo, de forma integral, não havendo um foco estreito na doença ou nos sintomas que o paciente apresenta, pois são considerados seus aspectos biopsicossociais, como suas preferências, seu bem-estar, e o contextos social e cultural (The Health Foundation, 2014).

Tendo em vista as práticas de cuidado em saúde de fundamentação holística, como é o caso da ACP e do Humaniza SUS, é nosso interesse compreender e analisar, através da Abordagem Centrada na Pessoa, da literatura e dos resultado de pesquisas sobre o tema, o que as pacientes gestantes ou puerperais - mulheres que se encontram no pós-parto -, de alto risco, internadas em uma enfermaria de ginecologia e obstetrícia, têm a dizer sobre as relações que a equipe multiprofissional de cuidado estabeleceram com elas durante o processo de hospitalização; identificar as percepções das pacientes internadas sobre o tipo de relação de cuidado recebido; e verificar, a partir das próprias participantes, a implicação das relações de cuidado no seu processo de hospitalização. Trata-se, assim, do desvelamento das significações pessoais atribuídas pelas pacientes acerca dos relacionamentos vivenciados durante a internação hospitalar e que durante a entrevista provocaram uma afetação emocional imediata.

\section{0 desenho de uma pesquisa sobre as relações humanas}

A pesquisa foi submetida ao Comitê de Ética em Pesquisa e obteve aprovação, com o Certificado de Apresentação para Apreciação Ética (CAAE) $n^{\circ}$ 45605115.8.0000.5541. Conduzimos a mesma conforme as diretrizes e as normas regulamentadoras de pesquisas envolvendo seres humanos, aprovadas pela Resolução n ${ }^{\circ} 466$, de dezembro de 2012, do Conselho Nacional de Saúde (Brasil, 2012).

Os dados foram coletados na Clínica de Ginecologia e Obstetrícia de um Hospital de ensino na cidade de Cuiabá, Mato Grosso. Para a seleção das participantes utilizamos como referência os seus prontuários. Foram selecionadas aquelas que atenderam aos critérios de inclusão, a saber: comprometimento cardiovascular, em que se atende a ênfase do Programa de Residência Multiprofissional, do qual o estudo faz parte; o tempo mínimo de quatro dias de internação, resultante das observações realizadas durante as entrevistas piloto frente a rotatividade nas altas hospitalares; e mulheres adultas, a partir de dezoito anos. Foram excluídas do estudo as pacientes que não atenderam aos critérios de inclusão e que não apresentaram assentimento com a realização da pesquisa.

No total participaram onze pessoas com idades entre vinte e quarenta anos. Dessas entrevistadas, cinco eram gestantes e seis puerperais. Seis delas com idades entre vinte e vinte e nove anos, quatro na faixa etária compreendida entre trinta e trinta e nove anos, e uma com quarenta anos de idade. Sobre o tempo de internação, mais da metade das participantes (sete entrevistadas) tinham entre sete e nove dias de internação quando realizadas as entrevistas, três participantes estavam internadas entre quatro e seis dias, e apenas uma estava internada a mais de dez dias. As voluntárias foram esclarecidas quanto aos objetivos do estudo, asseguradas do sigilo e convidadas a manifestar sua anuência com a assinatura do termo de consentimento livre e esclarecido (TCLE).

A coleta das informações ocorreu no segundo semestre de 2015, a partir das gravações em áudio de onze entrevistas focalizadas (Gil, 1999), utilizadas como um procedimento com a menor estruturação possível permitindo retomar ao objetivo da pesquisa quando necessário, com o uso das questões abertas: Como você está sentindo esse contato com a equipe? O que você pode dizer sobre o tipo de cuidado que está recebendo? Você acredita que essa relação contribui, dificulta... para a sua melhora?

Durante as entrevistas a pesquisadora buscou, a partir dos pressupostos que fundamentam a ACP, criar um clima de segurança e apoio, que auxiliasse no processo das entrevistas com as participantes. Buscamos durante o processo das entrevistas e por meio do uso das atitudes facilitadoras dar ênfase aos aspectos afetivos e em acentuar a situação imediata vivenciada pelas pacientes, a fim de que não somente os conteúdos informativos ou cognitivos se explicitassem, mas também aqueles ligados ao afeto.

O processamento dos dados se deu pela utilização do software de Análise Lexical Contextual de um Conjunto de Segmentos de Texto (ALCESTE), desenvolvido por Max Reinert no Centro Nacional Francês de Pesquisa Científica (CNRS). Esse é um programa que fornece a classificação estatística dos enunciados em khi2, de análise lexical, que quantifica um texto para extrair dele as estruturas mais significativas em Classes de palavras, apresentadas graficamente através de uma árvore de classificação hierárquica descendente (CHD), no formato de um dendograma, que serão analisadas qualitativamente (Camargo, 2005).

$\mathrm{O}$ aproveitamento do material discursivo foi de $74 \%$, com uma unidade de contexto inicial contendo onze entrevistas, e resultou na produção de sete subcategorias de Classes de palavras, que serão analisadas concomitantemente com as discussões que Rogers apresenta sobre as relações de ajuda, o levantamento da literatura e pesquisas consultadas concernentes ao tema.

\section{Significações das gestantes sobre as relações estabelecidas com a equipe multiprofissional}

A Figura 01 exibe o processamento dos dados a partir do software ALCESTE, que apresentou sete subcategorias das Classes de palavras. Consideramos como Eixo as três grandes subdivisões do 


\section{Significações das gestantes sobre as relações estabelecidas com a equipe}

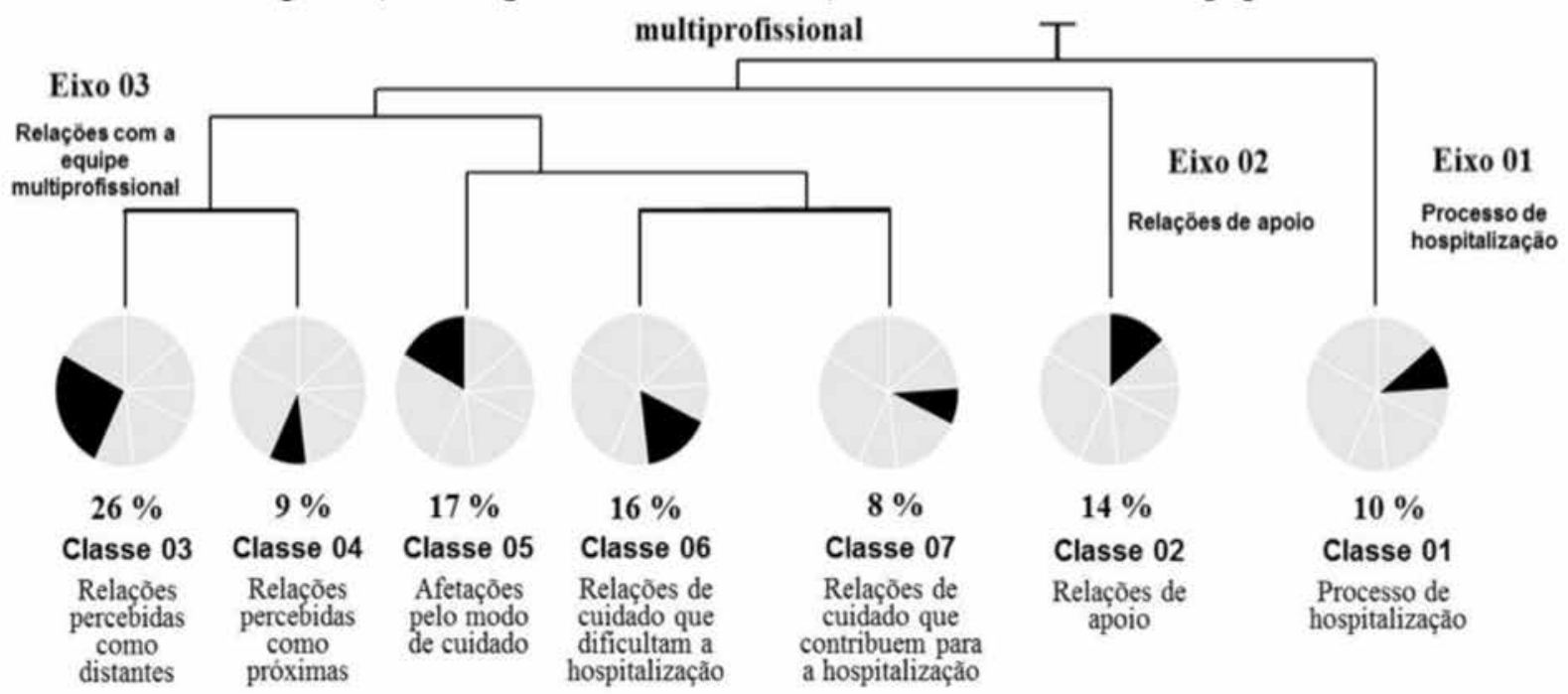

Figura 1. Dendograma da CHD resultante do processamento do corpus pelo software ALCESTE.

material discursivo. O Eixo 01 e o Eixo 02 foram denominados de Processos de hospitalização e Relações de apoio, com respectivamente 10\% e 14\% do discurso. Ao analisar o conteúdo e a posição desses Eixos no dendograma, que se apresenta como periférico ao Eixo 3, uma observação inicial se impõe: tais Eixos foram explicitados mediante a incorporação de um mote indutor - Como está sendo a sua internação?-, como recurso metodológico, após a realização do estudo piloto, a fim de que as participantes pudessem se sentir mais à vontade para a realização da pesquisa.

Essa questão introdutória, que também zela pela atmosfera facilitadora, traz um fator que, segundo Kinget (1977), é notado principalmente no começo das relações, em que o cliente - no caso específico do estudo, as participantes - está preso a angústias que podem torná-las hipersensíveis. Segundo a autora, em qualquer situação interpessoal a atmosfera só será permissiva se for composta por qualidades de segurança, externa e interna, e calor.

Dessa forma, o Eixo 01 e o Eixo 02 não abarcaram os objetivos da pesquisa, mas ajudarão a compreender o campo experiencial- fomentados por tudo aquilo que se passa no organismo, acessado pela memória, no qual as experiências passadas podem afetar a experiência imediata (Kinget, 1977)-, das participantes e sobre as coisas que as mesmas escolheram compartilhar.

Em contrapartida, o Eixo 03, Relações com a equipe multiprofissional, que compreende $76 \%$ do material, ao trazer cinco Classes de palavras - Relações percebidas como distantes (26\%), Relações percebidas como próximas (09\%), Afetações pelo modo de cuidado (17\%), Relações de cuidado que dificultam a hospitalização (16\%) e Relações de cuidado que contribuem para a hospitalização (08\%) -, forneceram os elementos de exploração do processo experiencial vivenciado pelas gestantes nas rela- ções interpessoais com a equipe multiprofissional, respondendo de forma particular aos objetivos da pesquisa.

\subsection{A hospitalização e a importância do apoio social}

O Eixo 01 foi composto por uma única Classe, cujo conteúdo e dados estatístico são detalhados pela Tabela 1 seguinte.

Tabela 1. Palavras Mais Relevantes da Classe Processos de Hospitalização

\begin{tabular}{|c|c|c|c|}
\hline \multicolumn{4}{|c|}{ Classe 01} \\
\hline Palavra & khi2 & Frequência & Percentual \\
\hline Comendo & 106 & 19 & $100 \%$ \\
\hline Vomit $^{1}$ & 88 & 13 & $100 \%$ \\
\hline Certinh $^{2}$ & 34 & 6 & $83 \%$ \\
\hline Control $^{3}$ & 24 & 6 & $63 \%$ \\
\hline Comec $^{4}$ & 22 & 10 & $47 \%$ \\
\hline $\mathrm{Mat}^{5}$ & 20 & 6 & $67 \%$ \\
\hline Horário & 20 & 4 & $67 \%$ \\
\hline Tom $^{6}$ & 11 & 7 & $38 \%$ \\
\hline Náusea & 10 & 3 & $67 \%$ \\
\hline Morrendo & 10 & 2 & $67 \%$ \\
\hline
\end{tabular}

Nota. ${ }^{1}$ vomitando, vomitar, vomitava, vomitei, vomito; ${ }^{2}$ certinha, certinho; ${ }^{3}$ controlado, controlar, controle; ${ }^{4}$ começa, começando, comecei, começo, começou; ${ }^{5}$ mata, matando; ${ }^{6}$ tomando, tomar, tomei.

Ao observar as palavras explicitadas pela Tabela 1, percebemos que abarcam o que as participantes têm a dizer sobre a hospitalização. Explorando esses dados, através dos discursos das participantes, notamos as diferenças sentidas por elas entre o contexto, rotina hospitalar e o cotidiano vivenciado antes da internação. Percebem ao longo da hospitalização mudanças no seu modo de vida e também nos aspectos clínicos, conforme exemplificado pelo depoimento seguinte: 
"Na sua casa é diferente daqui, [aqui] você tem que comer de acordo com o seu tratamento. E na casa da gente não, porque você está ruim e ali você está passando mal, mas está comendo. E aqui não, aqui tudo é controlado e é com os horários certinho" (Participante 06, 12 dias de internação, 40 anos, comunicação pessoal, 22 de setembro, 2015).

A declaração coincide com as discussões realizadas por Silva e Graziano (1996) que pontuam que a pessoa quando hospitalizada passa a participar de um grupo social específico, o de pessoas adoecidas e internadas, onde são impostos papéis caracterizados por dependência. Nesse contexto o seu espaço físico é limitado, suas roupas e objetos pessoais são retirados, o horário de suas atividades lhe é imposto, entre outros aspectos. Trata-se de um atravessamento à vida comum da pessoa, que agora também ocupa o papel de paciente.

O ser humano não é apenas um corpo que adoece, é formado por aspectos subjetivos e objetivos que o fazem interagir com o mundo (Bacellar, 2009). Para lidar com as tensões que o corpo adoecido proporciona e com as imposições de uma nova rotina comum aos ambientes hospitalares, como horários das refeições pré-estabelecidos, horários para exames, visita clínica dos profissionais da saúde, professores e estudantes, diminuição da privacidade e permanência em um ambientes desconhecido, as pacientes necessitam procurar fontes de adaptação que se configurem em processos de bem-estar e qualidade de vida emocional.

O desenvolvimento da capacidade de flexibilidade diante das adversidades, perpassa pelo desenvolvimento das potencialidades do indivíduo que, por sua vez, é possibilitado pela tendência à atualização do organismo. Rogers pontua que as pessoas são portadoras de uma tendência ao crescimento e desenvolvimento de seus potenciais, uma capacidade para a reestruturação e reorganização do self, e, consequentemente do comportamento (Rogers, 2009; 1972).

A Tabela 02 explicita as palavras mais significativas do Eixo 02, Relações de apoio.

Tabela 2. Palavras mais significativas da Classe Relações de apoio

\begin{tabular}{|c|c|c|c|}
\hline \multicolumn{4}{|c|}{ Classe 02} \\
\hline Palavra & khi2 & Frequência & Percentual \\
\hline Marido & 83 & 19 & $83 \%$ \\
\hline Dor $^{1}$ & 54 & 27 & $56 \%$ \\
\hline Alivi $^{2}$ & 50 & 13 & $90 \%$ \\
\hline Forç ${ }^{3}$ & 45 & 20 & $67 \%$ \\
\hline Lado & 38 & 8 & $80 \%$ \\
\hline Falta & 37 & 23 & $67 \%$ \\
\hline Crise & 32 & 9 & $78 \%$ \\
\hline Machuc $^{4}$ & 32 & 6 & $100 \%$ \\
\hline Acalm $^{5}$ & 31 & 6 & $86 \%$ \\
\hline Apoi $^{6}$ & 22 & 7 & $67 \%$ \\
\hline
\end{tabular}

Nota. ${ }^{1}$ dor, dores; ${ }^{2}$ alivia, aliviando, aliviar, alivio; ${ }^{3}$ força, forças; ${ }^{4}$ machuca, machucada, machucando; ${ }^{5}$ acalmar; ${ }^{6}$ apoiada, apoiam, apoiando, apoiar.
O contexto dessa Classe marca, de modo geral, um discurso sobre as relações de apoio, aqui explicitado como apoio social, que corresponde as funções de apoio emocional, material e afetivo. Essas interações buscam fomentar sentimentos de ajuda aos sofrimentos decorrentes do contexto hospitalar e do adoecimento. São relações estabelecidas com os familiares, amigos, colegas de quartos, funcionários do hospital, conforme o depoimento de uma participante.

"[As colegas de quarto] tentam te acalmar ao máximo e tentam ver se essa dor passa. Uma dor de falta da casa. Sinto bastante apoiada, porque elas apoiam bastante. Elas ajudam bastante e alivia, alivia a falta do filho e alivia a falta de casa” (Participante 08, 07 dias de internação, 21 anos, comunicação pessoal, 07 de outubro, 2015).

As relações de apoio mencionadas auxiliam no processo satisfatório da internação hospitalar, as falas apontaram que o apoio social durante a gestação pode funcionar como um fator protetivo.

As relações empáticas estabelecidas entre as colegas de enfermaria contribuem para que as gestantes se sintam amparadas e acolhidas no ambiente hospitalar. Rogers (2009), aliás, aponta a importância da existência de uma compreensão empática para o processo de ajuda bem-sucedido. Entretanto, chamamos a atenção para o fato de que nem sempre as relações são significadas positivamente entre todas as pacientes de uma enfermaria coletiva.

As funções de apoio não buscam extinguir a dor física do paciente, que estão relacionadas, na sua grande maioria, às mudanças orgânicas e funcionais. Essas manifestações orgânicas se mesclam e se confundem com componentes psicológicos, onde a presença das pessoas, se satisfatória, ajuda a melhor lidar com o sofrimento psíquico causado pelo processo de hospitalização, tal como manifestado pelas participantes do estudo. Ao terem abordado sobre as diferenças sentidas na rotina com o processo de hospitalização e a importância do apoio social na dor subjetiva, ainda que pela influência de um mote indutor, conforme discutido anteriormente, as entrevistadas nos ajudaram a compreender o campo experiencial das relações estabelecidas com a equipe multiprofissional.

\subsection{Percepções sobre as relações de cuidado}

As Classes 03 e 04 - Relações percebidas como distantes, Relações percebidas como próximas, respectivamente -, expressam as percepções das pacientes internadas sobre o tipo da relação de cuidado recebido. Rogers (1961) pontua que as pessoas percebem o mundo que lhes rodeia de um modo singular, estas percepções constituem a sua realidade, o seu campo experiêncial. Nesse sentido, a percepção manifestada pela pessoa corresponde a sua própria experiência e a sua significação da realidade externa. É sobre esse aspecto que a análise dos dados se pautará, a percepção das pacientes sobre as relações que a equipe estabelece com elas. 
A tabela 03, seguinte, explicita os resultados da Classe 03.

Tabela 3. Palavras mais significativas da Classe Relações percebidas como distantes

\begin{tabular}{lccc}
\hline \multicolumn{4}{c}{ Classe 03 } \\
\hline \multicolumn{1}{c}{ Palavra } & khi2 & Frequência & Percentual \\
\hline Exame $^{1}$ & 56 & 34 & $86 \%$ \\
Esper $^{2}$ & 30 & 23 & $70 \%$ \\
Fal $^{3}$ & 28 & 61 & $49 \%$ \\
Ultrassom $_{\mathrm{Dia}}$ & 23 & 12 & $100 \%$ \\
Resultado & 21 & 29 & $59 \%$ \\
Med $^{4}$ & 20 & 7 & $100 \%$ \\
Sab & 18 & 21 & $58 \%$ \\
Professor & 18 & 33 & $50 \%$ \\
Equipe de medicina & 17 & 12 & $100 \%$ \\
\hline
\end{tabular}

Nota. ${ }^{1}$ exame, exames; ${ }^{2}$ esperado, esperando, esperar, esperava, espero; ${ }^{3} \mathrm{faz}$, fazemos, fazer; ${ }^{4}$ medica, medicas, medico, médicos, medo; ${ }^{5}$ sabe, sabem, saber, sabia, sabiam.

Nessa Classe notamos palavras que se referem a procedimentos hospitalares (exame, ultrassom, resultado). Recorrendo-se ao contexto do discurso das participantes, foi possível observar que para além dos procedimentos, as pacientes se referem ao manejo e comunicação de tais procedimentos, implicando em relação com a equipe de saúde. Ao abordarem a questão, queixam-se do distanciamento notado entre a equipe, sobretudo do profissional da medicina, que, segundo elas, se colocam menos comunicativos na explicação e realização dos procedimentos. As participantes percebem um ruído existente na comunicação, as participantes também significam as atitudes dos profissionais como de pouca implicação no seu processo de tratamento, como mostra o depoimento:

"Teve menina daqui que semana passada fugiu. Duas mães fugiram daqui, quando pegaram elas já estava saindo com mala, já iam sair. Porque? Queriam respostas e ninguém dava resposta, a equipe da GO[medicina] só falava para ela olhar o neném, para esperar o exame e que vamos fazer o exame, mas também não sabem que dia e nem que horas que iriam fazer esse exame. E assim você fica, e o pessoal tem a vida lá fora, tem gente esperando lá fora, tem coisas e não dá para esperar"(Participante 07, 06 dias de internação, 28 anos, comunicação pessoal, 29de setembro, 2015).

Esse depoimento aponta que os ruídos na comunicação, sobretudo pelas solicitações não atendidas, não ouvidas, podem ser percebidos como algo que contribui para o distanciamento entre as pessoas. Rogers (1983), ao descrever as experiências em comunicação, assinala que quando efetivamente ouvimos uma pessoa e os significados atribuídos por essa em cada momento do compartilhamento da experiência, ouvimos não somente as palavras, mas a pessoa mesma. Ao perceber que os seus significados pessoais íntimos foram acolhidos, o interlocutor se sente aliviado e aberto a processos de mudança.

A ausência dos espaços de diálogo, aqui observados como lacuna entre os procedimentos e a relação com a equipe, tendem a silenciar o paciente, principalmente enquanto ser autônomo que percebe, sente e pensa sobre o seu processo de hospitalização.

Ismael (2005) ao discutir a comunicação no meio médico considera que "[...] o paciente espera receber a atenção compatível com o seu estado de ansiedade e desamparo: essa é, para ele, a característica suprema do saber médico, mais que os diplomas que ele eventualmente ostente nas paredes" (p. 88). Apesar disso, na percepção das entrevistadas, algumas situações vivenciadas no Hospital de ensino denunciam uma relação que suscita desamparo, tal como explicitado por uma das participantes do estudo:

"Essa médica mesmo, essa interna que falou para mim que nunca mais, que não iria me dar mais remédio, ela sumiu. A interna nem sequer veio aqui para saber se estava bem e se minha filha estava bem, simplesmente sumiu, eu nunca mais vi ela aqui e era mais que uma obrigação dela me dar remédio, se estava sentindo dor ou não, era obrigação dela. [...] Eu sabia que estava perdendo líquido e o médico chegou a falar para a minha mãe que eu estava fazendo moagem. Não era moagem, uma mãe sabe quando está na hora e quando não está. Esperava uma maior atenção deles e que eles compreendessem mais." (Participante 01, 06 dias de internação, 31 anos, comunicação pessoal, 09 de setembro, 2015).

As considerações tecidas, ao que tudo parece indicar, se apoiam no que é discutido por Costa e Azevedo (2010) sobre as condições de empatia, onde nomeiam um paradoxo técnico-empático e apresentam o temor, pontuado por alguns médicos, de que "ao serem empáticos, se distanciam da técnica existente na identidade médica, um distanciamento do profissionalismo" (p. 266). De modo contrastante, Rogers (2009), ao discutir a importância de uma compreensão empática nas relações humanas interpessoais, mostra que quanto mais compreendemos empaticamente, tão maior será a proximidade das relações interpessoais e, consequentemente, do processo de ajuda.

Outro contraste ao posicionamento médico de que é falta de profissionalismo ser empático com seu paciente é encontrado em estudos que explicitam o que os pacientes consideram como sendo um bom médico, tal como a pesquisa realizada por Baronio e Pecora (2015) no mesmo Hospital de ensino dessa pesquisa. As pesquisadoras realizaram um estudo no contexto da Clínica Médica e apontaram que o ideal de médico para os pacientes é aquele que apresenta um cuidado afetivo, que considera e entende os aspectos psicológico-emocionais dos pacientes.

A quarta Classe - Relações percebidas como 
próximas-, e as palavras que mais a caracterizam podem ser apreciadas na Tabela 04.

Tabela 4. Palavras mais significativas da Classe Relações percebidas como próximas

\begin{tabular}{lccc}
\hline \multicolumn{4}{c}{ Classe 04 } \\
\hline \multicolumn{1}{c}{ Palavra } & khi2 & Frequência & Percentual \\
\hline Atender $^{1}$ & 86 & 13 & $100 \%$ \\
Lugar $^{2}$ & 53 & 6 & $86 \%$ \\
Explic $^{3}$ & 35 & 5 & $71 \%$ \\
Imaginava & 26 & 5 & $56 \%$ \\
Problema & 21 & 6 & $43 \%$ \\
Parto normal & 21 & 6 & $60 \%$ \\
Parto & 17 & 6 & $44 \%$ \\
cesariano & & & \\
Resolv & & 4 & $50 \%$ \\
Experiência & 15 & 2 & $67 \%$ \\
Momento & 13 & 6 & $29 \%$ \\
\hline
\end{tabular}

Nota. ${ }^{1}$ atender, atenderam, atenderem; ${ }^{2}$ lugar, lugares; ${ }^{3}$ explicam, explicar, explicaram, explicou; ${ }^{4}$ resolver, resolveram.

Por uma leitura única e exclusivamente dos vocábulos apresentados pela Tabela 04, o nome da Classe soa não estar contemplado, mas ao recorrermos ao contexto das palavras, sobretudo ao termo atender, com maior índice estatístico (khi2), as gestantes estão se referindo a percepção do atendimento de forma positiva; quando se referem a $e x-$ plicações, falam sobre procedimentos satisfatórios; e quando pronunciam imaginava, estão falando sobre as expectativas do processo.

A análise do conjunto total das palavras da Tabela 04 e do contexto dessas, possibilitou compreender que as relações foram percebidas como próximas - inclusive os procedimentos de parto, em que ganham importância como palavras significativas dessa Classe. As participantes foram mais bem esclarecidas pelos profissionais da equipe, de forma ampla, e da medicina, particularmente, sobre os procedimentos de parto, e, ainda, se perceberam como atuantes nesses processos, como observado no contexto dos depoimentos seguintes:

"Eles [nos] incluem no tratamento. Em outros lugares não, eles tentam te evitar o máximo [quando se quer] saber de tudo. [Em outros lugares] eles falam só o básico, por cima por assim dizer. Aqui não, eles te trazem e te passam todos os relatórios, te explicam tudinho e por detalhe. [...] Para mim foi muito surpreendente, que nem o meu parto, como se diz, era para ser parto cesariano. Aqui eles chegaram e perguntaram para mim se eu realmente queria o parto cesariano, ou se eu queria passar por um processo de parto normal. Se fosse [querer] o parto normal eles iriam fazer a indução. No dia explicou como é que era [realizado] e eu queria o parto normal e eles compreenderam."(Participante 04, 07 dias de internação, 20 anos, comunicação pessoal, 16 de setembro, 2015).

Ao se perceberem incluídas no seu processo de internação, sentem que as suas opiniões são consideradas e notam uma prontidão para as tentativas de solução das suas necessidades. As participantes se perce- bem, dessa forma, como ativas na relação e valorizadas. Ainda na Classe 04 as participantes consideram uma boa comunicação como uma interação que provoca proximidade, e também relacionam os processos de explicação dos procedimentos e rotinas do hospital como algo que contribui para construir sentimentos de segurança, como podemos observar:

"Eles tentaram me fazer sentir bem, tipo assim, [queriam] saber como eu estou, procuravam saber o que está acontecendo e se estava preparada para isso. Explicaram e procuraram saber se queria realmente isso, me compreenderam. Eles conversam com a gente, explicam toda a situação e eles tentam acolher a gente." (Participante 04, 07 dias de internação, 20 anos, comunicação pessoal, 16 de setembro, 2015).

Segundo esse depoimento fica explicitado que uma relação de proximidade é percebida como um cuidado afetivo e efetivo e que provém dos aspectos positivos decorrentes da forma como a equipe atua. Na percepção apresentada pelas participantes, para que ocorra uma relação de proximidade, que favoreça um papel inclusivo das pacientes e que possibilite se sentirem seguras, é fundamental uma boa comunicação e uma atenção para as necessidades da paciente por parte da equipe.

Para Rogers (Rogers \& Kinget, 1977b), segundo a sua teoria das relações interpessoais, uma relação de ajuda eficaz está apoiada em atitudes que facilitam esse processo. Atitudes que se primam por uma relação afetiva, por um cuidado, por um respeito, por uma atenção, que, quando estabelecidas,favorecem a perceber a relação de ajuda como eficaz. Quando esses elementos não estão presentes, por sua vez, a percepção fica entorno de uma relação geral, pouco atendida ou satisfatória.

\subsection{Cuidado técnico e afetivo}

A Tabela 05, Afetações pelo modo de cuidado, apresenta a percepção das participantes sobre as relações estabelecidas com a equipe multiprofissional durante a hospitalização, sobretudo com os profissionais da Enfermagem.

Tabela 5. Palavras mais significativas da Classe Afetações pelo modo de cuidado

\begin{tabular}{lccc}
\hline \multicolumn{4}{c}{ Classe 05 } \\
\hline \multicolumn{1}{c}{ Palavra } & khi2 & Frequência & Percentual \\
\hline Cuid $^{1}$ & 32 & 13 & $69 \%$ \\
Ajud $^{2}$ & 21 & 23 & $43 \%$ \\
Carinh $^{3}$ & 21 & 8 & $70 \%$ \\
Convers & 20 & 13 & $52 \%$ \\
Equipe de & 20 & 11 & $52 \%$ \\
enfermagem & & & \\
Pesso & 19 & 34 & $36 \%$ \\
Serviço & 19 & 5 & $83 \%$ \\
Pergunt & 17 & 11 & $48 \%$ \\
Raiva & 15 & 3 & $100 \%$ \\
\hline
\end{tabular}

Nota. ${ }^{1}$ cuida, cuidado, cuidam, cuidando, cuidar; ${ }^{2}$ ajuda, ajudando, ajudar ${ }^{3}$ carinho, carinhosa, carinhosos; ${ }^{4}$ conversa, conversam, conversando, conversar, converso; ${ }^{5}$ pessoa, pessoal, pessoas; ${ }^{6}$ pergunta, perguntam, perguntando, perguntas, perguntei. 
No conjunto das palavras apresentadas na Classe 05, somente uma, o elemento raiva, traz de forma implícita uma afetação com conotação negativa. O contexto em que essa palavra está inserida se refere as condições para superação de sentimentos de forma geral, e de raiva, particularmente, conforme exemplificado no depoimento:

"Ela sempre passou cantando e dando risada e alegre. A gente tem que ser assim eu acho. Está certo, [porque] apesar das coisas que passamos em casa, apesar da raiva, e que passamos nervoso. Mas a gente tem que [ser assim]. Isso ajuda na melhora, as vezes as pessoas chegam de casa no serviço e só de me olhar com alegria e dar um bom dia ajuda, não é com cara fechada." (Participante 03, 06 dias de internação, 21 anos, comunicação pessoal, 10 de setembro, 2015).

Dias et. al. (2008) aponta ser necessário para que a Enfermagem desenvolva práticas em saúde mais produtivas, mesclar duas esferas de cuidado: uma esfera mais objetiva, que se refere às técnicas e aos procedimentos; e outra mais subjetiva, que se baseiam em sensibilidades, criatividades e intuições para cuidar do outro. A esfera subjetiva está relacionada aos comportamentos espontâneos, que demonstram apoio, conforto e buscam proximidade com o paciente.

Segundo esses autores, os profissionais que mais interagem com os pacientes são aqueles da equipe de enfermagem, por esse motivo esses profissionais devem estabelecer uma forma de contato que irá transcender os procedimentos técnicos. A fim de atender a isso, devem ser estabelecidas relações empáticas entre o enfermeiro para com o paciente, trata-se do "toque afetivo" da enfermagem explicitado na Classe 05 a partir dos vocábulos: cuidado, ajuda, carinho e conversa, como observado na declaração:

"Sinto carinho e cuidado. Até mesmo através de conhecimentos não científicos das pessoas da equipe de enfermagem, como colocando gelinho para passar o enjoou da outra paciente. Não foi uma coisa que a equipe de medicina prescreveu, mas é uma coisa que eles acham que pode ajudar e vai lá e faz. Cuidado vai além, buscam ajudar. É isso mesmo. Aqui é diferente”(Participante 10, 08 dias de internação, 20 anos, comunicação pessoal, 23 de outubro, 2015).

As relações foram percebidas de forma em que não houvesse dissociação entre o cuidado técnico e afetivo com a equipe de enfermagem. Essas percepções afetaram as participantes e levaram a desencadear sentimentos de valorização pessoal e movimento de autocuidado em relação ao seu próprio processo. As participantes do estudo também explicitam que os funcionários mais amistosos seriam aqueles que gostam do seu papel e do trabalho que desempenham. A percepção de que o profissional gosta do trabalho se alinham com o entendimento de comprometimento e qualidade do trabalho, como foi pontuado por uma participante:
"Sinto que estou sendo bem atendida e que você tem um valor, que você não está, que elas não estão ali só fazendo o serviço dela de qualquer jeito. Elas estão gostando do que estão fazendo e está fazendo com carinho. Você tem que apreciar tudo que a pessoa faz por você, é porque às vezes ela está. Eu entendo que a equipe de enfermagem da madrugada perdem a noite, é o serviço delas, mas é complicado e elas mesmo assim atendem você com todo bom coração, vem e pergunta como é que você está, várias vezes a noite, eu acho isso bem interessante e é isso" (Participante 09, 08 dias de internação, 20 anos, comunicação pessoal, 20 de outubro, 2015).

Nas análises da Classe 05 observamos aquilo que as participantes perceberam sobre as relações estabelecidas com a equipe multiprofissional, com ênfase na equipe de enfermagem. Nas Classes seguintes veremos como as relações estabelecidas implicam e afetam o processo de hospitalização.

\subsection{Ser pessoa na hospitalização}

Com a Classe 06, Relações de cuidado que dificultam a hospitalização, apresentadas na Tabela 06, podemos notar como as participantes percebem e sentem as relações de cuidado que dificultam o seu processo de hospitalização.

Tabela 6. Palavras mais significativas da Classe Relações de cuidado que dificultam a hospitalização

\begin{tabular}{lccc}
\hline \multicolumn{4}{c}{ Classe 06 } \\
\hline \multicolumn{1}{c}{ Palavra } & khi2 & Frequência & Percentual \\
\hline Vida & 72 & 24 & $71 \%$ \\
Depend & 38 & 10 & $89 \%$ \\
Acab $^{2}$ & 29 & 15 & $57 \%$ \\
Difícil & 29 & 14 & $52 \%$ \\
Chat $^{3}$ & 27 & 5 & $100 \%$ \\
Import $^{4}$ & 18 & 7 & $67 \%$ \\
Sozinh & 18 & 7 & $67 \%$ \\
Pesso $^{6}$ & 16 & 19 & $33 \%$ \\
Situação & 15 & 7 & $54 \%$ \\
Saúde & 12 & 4 & $67 \%$ \\
\hline
\end{tabular}

Nota. ${ }^{1}$ depende, dependência, dependente, depender; ${ }^{2}$ acaba, acabam, acabou; ${ }^{3}$ chata, chato; ${ }^{4}$ importa, importando, importante, importar; ${ }^{5}$ sozinha, sozinho; ${ }^{6}$ pessoa, pessoal, pessoas.

As palavras presentes nessa Classe explicitam as dificuldades encontradas pelas gestantes durante a hospitalização, explicitadas na Tabela 6, sobretudo pelos elementos dependência, difícil, chato. Esses termos, percebidos a partir do campo experiencial das participantes, configuram conotações negativas diante de situações impeditivas, como o caso de uma hospitalização que está associado a impedimentos funcionais, como mostrado no depoimento:

"É complicado porque você se sente meio que incapaz. Às vezes você precisa de alguém para te ajudar a ir ao banheiro e essa situação que assim parece simples, mas que se torna muito chato ficar dependente dos outros. [...] Eu nunca gostei de depender de ninguém, mas aqui 
no hospital você acaba dependendo para ir ao banheiro, para pegar uma água, para te dar um remédio e é muito chato" (Participante 09, 08 dias de internação, 20 anos, comunicação pessoal, 20 de outubro, 2015).

A fala indica que a dependência, evidenciada pelo impedimento de executar suas próprias tarefas, devido à perda e alteração nas condições funcionais, é um dos estados que pode dificultar a hospitalização. Esse estado influencia o relacionamento com a equipe multiprofissional, já que as participantes se sentem incomodadas e receiam incomodar aqueles que se dispõe ao cuidado em saúde, pelo temor em estabelecer uma relação de cuidado que é sentida como dependência.

Em outras situações o estado de dependência também foi percebido pelas participantes como fruto das relações com a equipe multiprofissional. Elas dizem sobre as dificuldades em depender dos posicionamentos da equipe, tanto em relação à estadia e permanência na internação, quanto em relação a depender do outro para a solução dos sofrimentos de ordem biopsicossociais.

"Eu estou esperando chegar ao extremo para poder chamar eles. Sempre tem uns que me falam que já deu o remédio. O remédio é forte e não está passando, o que a gente faz agora e fica aquela questão. Para você resolver o seu problema, sendo que você não tem experiência nenhuma nessa área e você fica meio perdida. Fico preocupada como as pessoas que me olham se eu pedir um medicamento" (Participante 09, 08 dias de internação, 20 anos, comunicação pessoal, 20 de outubro, 2015).

Pelas falas das participantes observamos que as relações que dificultam a hospitalização se associam a perda da autonomia e ao sentimento de não terem sido compreendidas, como também ao sentimento de frustação perante a não resolutividade das suas demandas. Conforme aponta Rogers (1977) a noção de sentimento irá incluir, de modo concomitante, a experiência afetiva e a significação cognitiva desta experiência, a partir da forma que foi experimentado no momento imediato.

As entrevistadas parecem ter significado que a equipe multiprofissional dissocia a internação de seus processos vivenciais, conforme salienta uma das pacientes: "Parece que eles não estão nem se importando e acham que você está aqui em um hotel e pode esperar a hora que quiser porque tem comida" (Participante 07, 06 dias de internação, 28 anos).

A partir de relatos como o desta participante, foi possível perceber a existência do imaginário de que durante a internação, para a equipe, a vida "lá-fora” parece parar. Essa significação é de grande incômodo para as gestantes, já que durante a internação as questões vivenciais continuam existindo e implicando no seu modo de vida.

O sentimento de não serem reconhecidas pela equipe nas suas questões pessoais, conforme apre- sentado, provoca dificuldades no processo relacional. Mesmo que sejam sugeridos procedimentos necessários para a melhora clínica, as participantes trazem como fundamental a compreensão e a consideração de sua vida integral.

Notamos o quanto os profissionais da equipe multiprofissional necessitam estar atentos aos múltiplos fatores biopsicossociais que influenciam a experiência afetiva e a significação cognitiva, e consequentemente as relações interpessoais e o processo hospitalar das pacientes.

Na Classe 07, Relações de cuidado que contribuem para a hospitalização, última Classe a ser analisada, observamos como as participantes percebem as relações de cuidado que facilitam o seu processo de hospitalização.

Tabela 7. Palavras mais significativas da Classe Relações de cuidado que contribuem para a hospitalização.

\begin{tabular}{|c|c|c|c|}
\hline \multicolumn{4}{|c|}{ Classe 07} \\
\hline Palavra & khi2 & Frequência & Percentual \\
\hline Super $^{1}$ & 33 & 8 & $50 \%$ \\
\hline Pequeno & 33 & 3 & $100 \%$ \\
\hline Situação & 16 & 5 & $38 \%$ \\
\hline Reclamar & 14 & 3 & $50 \%$ \\
\hline $\mathrm{Sai}^{2}$ & 13 & 4 & $40 \%$ \\
\hline Criança & 13 & 2 & $67 \%$ \\
\hline Volt $^{3}$ & 9 & 2 & $50 \%$ \\
\hline Deus & 7 & 7 & $22 \%$ \\
\hline Coisa & 7 & 15 & $16 \%$ \\
\hline $\mathrm{Pass}^{4}$ & 7 & 18 & $17 \%$ \\
\hline
\end{tabular}

Nota. ${ }^{1}$ super, superar, superasse; ${ }^{2}$ sai, saia, saio; ${ }^{3}$ volta, voltar; ${ }^{4}$ passa, passam, passando, passar.

Notamos, recorrendo ao contexto das palavras presentes na Tabela 7, que elas explicitam as relações de cuidado oferecidas pela equipe multiprofissional, como também apontam para o suporte que as gestantes constroem para lidar com as dificuldades em um processo de hospitalização.

Nessa Classe as pacientes mencionam o tratamento interpessoal como fator que tanto irá contribuir para a hospitalização, quanto para a melhora do quadro geral de saúde. Caprara e Rodrigues (2004), aliás, consideram que uma melhor relação médico e paciente - equipe de saúde e paciente -, irá influenciar diretamente o estado de saúde dos pacientes, como verificado no depoimento seguinte:

"A equipe_da_GO tem uns cuidados bem próximo mesmo porque aqui é assim, todo mundo trata você bem, toda hora eles estão aqui e eles passam olhando, eles conversam e então você já até anima mais. Trata muito bem, nossa, muito bem mesmo. Depois que eu sair daqui a minha vida é outra coisa. [...] Aqui eu tive apoio, eu tive apoio, apoio de todo mundo. Se eu estou boa assim é por causa da equipe_da_GO, é por causa que eles me ajudaram muito." (Participante 06, 12 dias de internação, 40 anos, comunicação pessoal, 22 de setembro, 2015). 
Pelo depoimento é manifesto que o tratamento eficaz para as participantes do estudo é aquele que consegue ser centrado nas pacientes, enquanto pessoas, e não centrado em procedimentos de rotina. Disto se verifica a importância de uma ambiência composta por relações de ajuda integral, em consideração as dimensões biopsicossociais, que reforça o paradigma holístico nos cuidados de saúde, no qual as ciências humanas e sociais contribuem para os processos de humanização dos cuidados, e de modo concomitante para a melhora na saúde.Dessa forma irão considerar as atitudes necessárias para lidar com a situação vivenciada e as suas implicações pessoais, conforme comunica uma das participantes:

"Apesar de eu saber que quero ir embora, que eu já não aguento mais ficar aqui, não por falta do carinho e da atenção que eu tenho dos profissionais daqui, mas sei e eu entendo o porquê eu estou aqui. Sei que eu tenho que estar aqui para evitar uma complicação lá fora e ter que voltar de novo. Eles querem que eu saia daqui cem por cento, tanto eu quanto o meu neném." (Participante 05, 08 dias de internação, 37 anos, comunicação pessoal, 18 de setembro, 2015).

Com o cuidado centrado na pessoa, é notória a abertura das participantes para as atualizações das suas necessidades, como também o desenvolvimento de uma liberdade, cada vez maior, para lidar com as suas experiências, contribuindo nas relações de ajuda para a adesão ao tratamento e fomento de confiança.

Quanto às relações de confiança, Rogers (2009) cita um estudo realizado por Whitehorn e Betz em 1954, em que os autores separaram jovens médicos em dois grupos (A e B) e analisaram o sucesso alcançado pelo Grupo A no trabalho com pacientes esquizofrênicos em uma enfermaria psiquiátrica. A partir das conclusões desse estudo, Rogers chama a atenção para o fato de que o sucesso dos médicos do Grupo A, na ajuda prestada aos pacientes esquizofrênicos, tenha se dado em razão dos médicos desse grupo estabelecerem relações de confiança,recorrendo a uma participação pessoal ativa, de pessoa para pessoa - nas análises das interações entre esses médicos com seus pacientes, foi concluído que ocorreu maior valorização das significações pessoas apresentadas pelos pacientes.

De forma similar, as participantes de nosso estudo argumentam que quanto mais se sentem compreendidas, maior é a chance de confiarem na equipe e se tornarem abertas a ajuda oferecida pela equipe multiprofissional.

\section{Considerações Finais}

Com o objetivo de compreender o fenômeno da percepção, a partir das significações pessoais, optamos como recurso metodológico a utilização de entrevistas focalizadas, orientadas por questões abertas que possuíam a finalidade de auxiliar as entrevistas através do acesso e da focalização, não somente dos conteúdos afetivos presentes, mas também dos conteúdos que pudessem esclarecer sobre os objetivos do estudo. Destacamos que a condução das entrevistas focalizadas trata-se de um procedimento rigoroso e que demanda do pesquisador um preparo teórico e técnico, como também necessita da constante observância do processo de pesquisa, que é atravessado pelo fenômeno estudado, pelo contexto onde a pesquisa é realizada e pelo campo experiencial do entrevistador e das participantes.

Recorrendo a prática reflexiva, após os processos de coleta e análise dos dados, ficou evidente que a utilização das questões abertas durante a entrevista, mais se prestou ao aprofundamento dos objetivos do estudo, do que ao próprio processo experiencial das participantes, permitindo a consideração de que a utilização das questões abertas durante a entrevista pode ser dispensável, diferentemente de quando abordado como questão introdutória para o processo que se tornará experiencial.

Essa experiência permitiu refletir sobre o papel da entrevista e do entrevistador em pesquisas orientadas pela ACP, no qual a criação de um clima facilitador empreendido para a coleta de entrevistas para fins de pesquisa, ainda que compreenda um objeto de investigação, deve levar em conta as mesmas atitudes facilitadoras- consideração positiva incondicional, congruência e compreensão empática -, consideradas por Rogers nas relações de ajuda psicológica, sem a necessidade de recorrer a outros procedimentos metodológicos, como as questões abertas no decorrer das entrevistas. Ao criarmos um clima facilitador proporcionamos um espaço de apoio e segurança, no qual as participantes se sentiram mais confortáveis para falar sobre suas percepções durante as entrevistas e sobre as relações que estabeleceram com a equipe multiprofissional.

Considerando o desenvolvimento da ACP e a Teoria das relações humanas apresentada por Rogers, percebemos que os fundamentos presentes nessa pesquisa e as formas de comunicação entre a pesquisadora e as participantes estão relacionados com a Fase Reflexiva, nesta ocorre um fluxo bilateral na comunicação, com uma maior expressão de uma escuta ativa, no qual o foco está na promoção e no desenvolvimento do cliente - participante - em uma atmosfera desprovida de ameaça, isto é, em um clima facilitador e sendo efetivadas, pelo menos em um grau mínimo, as condições facilitadoras (Moreira, 2010).

Verificamos através da análise do corpus que as percepções das relações interpessoais com a equipe multiprofissional são influenciadas pelo campo experiencial das participantes.Uma mesma pessoa pode ter percepções diferentes em situação diferentes, e, ainda, pessoas distintas podem perceber de forma diferente a mesma situação. O campo experiencial, constituído também por experiências passadas, mas presentes no aqui e agora das situações, fomenta as percepções das participantes em relação ao significado pessoal que atribuem as suas experiências na hospitalização. 
Enfatizamos que ao estudar as percepções das participantes, estamos diante de dois fenômenos: o perceptivo, conforme descrito anteriormente, e o de distorção da percepção (Rogers, 1977). Assim, as percepções encontradas nesse estudo não apresentam o fato real, mas sim a significação das experiências atribuída pelas participantes, enquanto expressão dos seus mundos internos.

Nesse estudo, assim, as participantes perceberam relações de proximidade e de distanciamento com a equipe de saúde. Quando falam sobre as relações próximas estão considerando como fator primordial uma comunicação satisfatória. Nestas destacam as explicações da equipe multiprofissional sobre os procedimentos hospitalares, principalmente com relação às explicações dadas pela equipe da medicina, e quando isso ocorre se sentem incluídas no seu processo de hospitalização. Relatam, ainda, haver uma maior comunicação quanto às formas de parto, que pode ser resultado das políticas de saúde, que incentivam o protagonismo das mulheres durante esse processo.

Sobre as relações de distanciamento as participantes apontam ruídos na comunicação dos procedimentos rotineiros, como ultrassom e exames, que interfere no grau de aproximação e distanciamento das relações com a equipe. Diante da rotina hospitalar o cuidado na explicação sobre esses procedimentos, básicos na internação, parece não estar sendo considerado, podendo acarretar dificuldades na hospitalização, sobretudo na adesão ou não aos procedimentos solicitados.

Mais significativa se torna a atenção a ser dada aos procedimentos rotineiros, quando recorremos aos resultados que apontam as relações de distanciamento com mais de o dobro das explicitações comparadas às relações percebidas como próximas. Os procedimentos rotineiros, assim, necessitam receber a devida atenção e comunicação pelos profissionais de saúde.

Observamos, ainda, que quando as participantes enfatizam os relacionamentos distantes, destacam os profissionais da Medicina, e quando falam sobre as relações percebidas como mais afetivas, a ênfase recai sobre os profissionais da Enfermagem. Esses resultados indicam haver diferenças que podem se associar a formação profissional.

Entretanto, vale ressaltar que independentemente da ênfase concedida às diferentes categorias profissionais, a pesquisa revela que os discursos das participantes apresentam uma maior evidência nas relações percebidas como distantes, em detrimentos as próximas. Isso reverbera na necessidade de se considerar a disposição dos profissionais na interação com os pacientes, a efetivação das políticas públicas que se referem à humanização da saúde,e as formas de cuidado e promoção de saúde que possam transformar e potencializar os relacionamentos na hospitalização.

Esse estudo destacou a necessidade da atenção para: a) a comunicação dos procedimentos; b) a disposição para cuidados afetivos em que consideram a pessoa como centro em detrimento às técnicas; c) a importância para as significações pessoais; como também, d) as implicações das significações pes- soais no processo de hospitalização. Exercer essas diferenças na atenção ao paciente pode contribuir para o desenvolvimento dos relacionamentos na ambiência hospitalar, que facilitem a hospitalização.

Também observamos, ao discutir os processos perceptivos, o quanto os estados psicológicos devem ser considerados pelos profissionais de uma equipe multiprofissional de saúde hospitalar, uma vez que o mesmo atua como filtro nas comunicações e relações estabelecidas.

Assim, a percepção de ajuda eficaz por parte das pacientes, se mostra interdependente de quatro fatores indissociáveis: de uma comunicação cuidadosa de procedimentos, de uma escuta sensível das demandas e solicitações do paciente, do estabelecimento de uma relação respeitosa, por parte dos profissionais de saúde; e de certa congruência interna que permita uma percepção com a menor distorção possível, por parte dos pacientes.

Muitas situações e fatores biopsicossociais vivenciados durante a internação podem oferecer uma ameaça a imagem de si, dessa forma a simbolização dessas experiências fica impedida devido ao seu conteúdo ameaçador, contribuindo com as deformações da experiência imediata. Dar atenção para um cuidado que seja centrado na pessoa que está internada, facilitando um clima que seja de segurança, contribui para que os elementos da experiência dessa pessoa possam ser mais corretamente simbolizados, possibilitando um processo para consciência de si, do outro e das relações humanas, de cuidado em saúde, presentes no ambiente hospitalar, que se manifesta como mais um dos campos de aplicação da Teoria das Relações Humanas de Rogers (Rogers, 1977), ao lado das relações familiares, educação e da aprendizagem, direção de grupos, resolução de tensões e de conflitos de grupos.

\section{Referências}

Araújo, K. M. de \& Leta, J. (2014). Os hospitais universitários federais e suas missões institucionais no passado e no presente. História, Ciências, Saúde. Manguinhos, Rio de Janeiro, 21(4), 1261-1281.

Bacellar, A. (2009). Humanização no contexto hospitalar: A Abordagem Centrada na Pessoa como recurso para humanização hospitalar. Em A. Bacellar (Cord.), A Psicologia Humanista na Prática: reflexões sobre a prática da Abordagem Centrada na Pessoa. Palhoça, SC: Ed. Unisul.

Baronio, M., \& Pecora, A. R. (2015). A relação de cuidado na perspectiva de médicos e pacientes durante a internação em hospital-escola. Psicologia Revista: São Paulo, 24(2), 199-228.

Brasil. Ministério da Saúde. Conselho Nacional de Ética em Pesquisa - CONEP. (2012). Resolução $n^{o}$ 466, dez. 2012. Dispõe sobre as diretrizes e normas regulamentadoras de pesquisas envolvendo seres humanos. Disponível em http://conselho. saude.gov.br/resolucoes/2012/Reso466.pdf. 
Brasil. Ministério da Saúde. Secretaria de Atenção à Saúde. Núcleo Técnico da Política Nacional de Humanização. (2008). Humaniza SUS:documento base para gestores e trabalhadores do SUS. $4^{\mathrm{a}}$ ed. Brasília: editora do Ministério da Saúde.

Camargo, B. V. (2005). Alceste: um programa informático de análise quantitativa de dados textuais. Em A. S. P. Moreira, et al. (Orgs.), Perspectivas teórico-metodológicas em representações sociais. João Pessoa: UFPB. Editora Universitária, 511539. Disponível em: http://www.laccos.org/pdf/ Camargo2005_alc.pdf.

Caprara, A., \& Rofrigues J. (2004). A relação assimétrica médico-paciente: repensando o vínculo terapêutico. Ciênc. Saúde Coletiva. 9(1), 139-146.

Costa F. D., \& Azevedo R. C. S. (2010). Empatia, relação médico-paciente e formação em medicina: um Olhar Qualitativo. Rev Bras Educ Med. 34(2), 261-269.

Dias A. B., Oliveira L., Dias D. G., \& Santana, M. G. (2008). O toque afetivo na visão do enfermeiro. Rev Bras Enferm. 61(5), 603-607.

Gil, A. C. (1999). Métodos e técnicas de pesquisa social. 5.ed. São Paulo: Atlas.

Ismael, J. C. (2005).O médico e o paciente: breve história de uma relação delicada. 2 ed. rev. ampl. São Paulo: MG Editores.

Kinget, G. M. (1977). Primeira parte. In C. R. Rogers, \& G. M. Kinget (Org.).Psicoterapia e relações humanas. v. 1. Belo Horizonte: Interlivros (Originalmente publicado em 1959).

Moreira, V. (2010). Revisitando as fases da Abordagem Centrada na Pessoa. Estudos de Psicologia.Campinas. 27(4), 537-544.

Rogers, C. R. (2009). Tornar-se Pessoa. $6^{\mathrm{a} e d . ~ S a ̃ o ~ P a u l o: ~}$ WMF Martins Fontes (Originalmente publicado em 1961).

Rogers, C. R. (1972). Grupos de encontro. Lisboa: Moraes Editores (Originalmente publicado em 1970).

Rogers, C. R. (1977). Segunda parte. In C. R. Rogers, \& G. M. Kinget (Org.). Psicoterapia e relações humanas. v. 1. Belo Horizonte: Interlivros (Originalmente publicado em 1959).

Rogers, C. R. (1983). Um jeito de ser. São Paulo: E.P.U. (Originalmente publicado em 1980).

Rogers, C. R. (1994).As condições necessárias e suficientes para a mudança terapêutica da personalidade. Em J. K. Wood (Org.), Abordagem centrada na pessoa. Vitória: Editora Fundação Ceciliano Abel de Almeida (Originalmente publicado em 1957).
Rogers, C. R., \&Kinget, G. M.(1977b.). Psicoterapia e relações humanas. v. 2. Belo Horizonte: Interlivros (Originalmente publicado em 1959).

Silva, M. J. P. da., \& Graziano, K.U. (1996). A abordagem psico-social na assistência ao adulto hospitalizado. Revista da Escola de Enfermagem da USP: São Paulo, 30(2), 291-296.

The Health Foundation. (2014) Person-centred care made simple: what everyone should know about person-centred care. London; The Health Foundation. Disponível em: https:/www.health.org. uk/sites/default/files/PersonCentredCareMadeSimple.pdf.

Leihge Roselle Rondon Pereira: Psicóloga, Mestra em Psicologia pela Universidade Federal de Mato Grosso (PPGPSI/UFMT). Especialista em Psicologia da Saúde pelo Programa de Residência Integrada Multiprofissional em Saúde do Adulto e do Idoso com ênfase na Atenção Cardiovascular do Hospital Universitário Júlio Müller (PRIMSCAV/HUJM/ UFMT). Especialista em Psicologia Hospitalar pelo Conselho Federal de Psicologia. E-mail: leihgeroselle@gmail.com.

Ana Rafaela Pecora Calhao: Psicóloga, Doutora em Psicologia Social pela Universidade do Estado do Rio de Janeiro, com Formação na Abordagem Centrada na Pessoa (ACP) pelo Centro de Psicologia da Pessoa do Rio de Janeiro, orientação teórica e metodológica de atuação. Professora Associada do Departamento de Psicologia da Universidade Federal de Mato Grosso (UFMT) e do Programa de Pós-graduação em Psicologia (PPGPSI/UFMT). Coordenadora e Supervisora/ACP do Aperfeiçoamento em Psicologia Clínica/UFMT. Coordenadora de Pesquisa do curso de graduação em Psicologia da UFMT. Foi Tutora, Professora e Orientadora de Pesquisa do Programa de Residência Multiprofissional, com ênfase em atenção cardiovascular, do Hospital Universitário Júlio Müller (PRIMSCAV/HUJM/UFMT), de 2010-2018. E-mail: arpecora@terra.com.br.

Recebido em 12.12.2016 Primeira decisão editorial em 11.02.2018 Aceito em 20.04.2018 